\title{
Effect of Lemongrass Essential Oil based Mouthwash against Microflora Associated with Dental Plaque
}

\author{
Sonia Ambade ${ }^{1 *}$ (D), Neelima Deshpande ${ }^{2}$ and Pragati Abhyankar ${ }^{1}$ (D) \\ ${ }^{1}$ Department of Microbiology, H.V. Desai College, Pune - 411 002, Maharashtra, India. \\ ${ }^{2}$ Department of Microbiology, A.G. College, Pune - 411 004, Maharashtra, India.
}

\begin{abstract}
Mouthwash is one of the most convenient and effective method employed for dental plaque management. The aim of the undertaken study was to establish the antimicrobial and anti-biofilm properties of lemongrass essential oil (LGEO) based mouthwash on microbial flora from dental plaque and also check cytotoxicity of mouthwash formulation. Five main colonizers of dental plaque representing dental microflora and three different bacterial species mainly responsible for the formation of biofilm were selected in this study. LGEO based mouthwash was developed and its stability was also determined. The antimicrobial and anti-biofilm activity of LGEO based mouthwash has been evaluated against the representative dental microflora as per CLSI guidelines. Cytotoxicity of mouthwash was checked by globally used MTT assay employing NIH 3T3 mouse fibroblast cell line. The mouthwash has been found to exhibit the stability in its major component, citral and also found exhibit antimicrobial and anti-biofilm activity against dental microflora. No cytotoxic effect was observed on mouse fibroblast cell line. LGEO in formulated mouthwash being a natural, herbal material isolated from traditional medicinal plants appears as a good and effective substitute to control the microflora linked with dental plaque.

Keywords: LGEO, Dental flora, Mouthwash, MTT Assay
\end{abstract}

*Correspondence: drsoniaambade@gmail.com

(Received: September 5, 2021; accepted: December 2, 2021)

Citation: Ambade S, Deshpande N, Abhyankar P. Effect of Lemongrass Essential Oil based Mouthwash against Microflora Associated with Dental Plaque. J Pure Appl Microbiol. 2022;16(1):174-181. doi: 10.22207/JPAM.16.1.06

C The Author(s) 2022. Open Access. This article is distributed under the terms of the Creative Commons Attribution 4.0 International License which permits unrestricted use, sharing, distribution, and reproduction in any medium, provided you give appropriate credit to the original author(s) and the source, provide a link to the Creative Commons license, and indicate if changes were made. 


\section{INTRODUCTION}

Oral micro-organisms have a major function in biofilm formation which would lead to the development of dental caries, and controlling its activities can definitely prevent dental caries. Dental plaque is one of the etiologic factors in gingival and periodontal disease. Daily cleaning of dental plaque is one of the prime factors in the prevention of caries, periodontitis and gingivitis. Both of these conditions are plaque associated and therefore removal of dental plaque routinely should inhibit their occurrence as well as progression. ${ }^{1}$ Periodontal disease, including gingivitis and periodontitis, is one of the most common oral diseases. The major etiologic bacteria of gingivitis are Actinomyces, Streptococcus, Fusobacterium, Veillonella and Treponema species. The principal microorganisms associated are mostly an anaerobic and facultative anaerobic bacteria such as Porphromonas gingivalis, Prevotella intermedia, Aggreatibacter actinomycetemcomitans and Tannerella forsythia. ${ }^{2}$

For thousands of years across the globe, the medicinal plants have been used as a source for safe drugs. They are therefore, receiving considerable attention due to their pharmacological effects such as antimicrobial, anticarcinogenic, and antioxidant properties. ${ }^{3}$ Essential oils represent a cheap and effective antiseptic topical treatment option even for antibiotic-resistant strains as Methicillin-Resistant Staphylococcus aureus (MRSA). ${ }^{4}$ Cymbopogon citratus, commonly known as lemon grass has been in cultivation in South Asian countries for many years and is used for medicinal purposes. Antioxidant, antidepressant, antiseptic, fungicidal, bactericidal, astringent, and sedative properties of lemon grass have been explored and documented. ${ }^{5}$ Lemon grass essential oil (LGEO) was found effective against dental flora. ${ }^{6}$

This study aims to evaluate the antibacterial and anti-biofilm activity of LGEO based mouthwash against Streptococcus mutans and Lactobacillus acidophilus oral bacteria.

\section{MATERIALS AND METHODS}

\section{Isolation and identification of microflora}

Samples of dental plaque were collected with the help of a dental clinician in Pune. The observable plaque present at the gingival was collected using a sterile probe, and dispensed in sterile Eppendorf tubes containing $1 \mathrm{~mL}$ sterile Phosphate Buffered Saline (PBS). These collected samples were then transported to the laboratory at $6^{\circ} \mathrm{C}$ to $10^{\circ} \mathrm{C}$ and were processed immediately.

In the laboratory, samples were first homogenized using vortex mixer. $100 \mu \mathrm{L}$ of sample was inoculated in the liquid enrichment broth and incubated at $37^{\circ} \mathrm{C}$ for $24 \mathrm{~h}$. The enriched broth was again mixed by vortexing and a loopful $(10 \mu \mathrm{L})$ of sample was streaked on sterile Mannitol Salt Agar, sterile de Man, Rogosa and Sharpe agar (MRS), sterile Mitis Salivarius (MS) agar. The plates were incubated for 24 to 48 hours at $37^{\circ} \mathrm{C}$ in aerobic conditions. However, for MRS medium, incubation was carried out in microaerophilic conditions. Colony characteristics were noted down after incubation and saline suspension of overnight culture was prepared. Gram staining was carried out and the hanging drop technique was followed for checking motility.

Molecular characterization to identify selected isolates was carried out using 165 rRNA gene amplification procedure as illustrated by

Table 1. Finalized test organisms for the study

\begin{tabular}{c}
\hline Microorganism procured from MTCC (with their ID number) \\
Streptococcus mutans (890) \\
Streptococcus oralis (2696) \\
Lactobacillus acidophilus (10307) \\
Lactobacillus rhamnosus (1408) \\
Candida albicans (4748) \\
\hline Microorganism isolated from dental plaque (with GenBank accession number) \\
Streptococcus agalactiae (MH793435) \\
Staphylococcus epidermidis (MH793436) \\
Lactobacillus fermentum (MH793437) \\
\hline Journal of Pure and Applied Microbiology $\quad 175 \quad$ www.microbiologyjournal.org
\end{tabular}


Pidiyar et al. ${ }^{7}$ Bacterial isolates were recognized based on 16S rRNA gene sequence homology by means of the reference sequences available in GenBank. A strain is regarded as a member of species if the sequence homology is more than $98.2 \% .^{8}$ Accordingly the three isolates got identified as Streptococcus agalactiae, Staphylococcus epidermidis and Lactobacillus fermentum all with homology $\geq 99 \%$. The gene sequence data of these isolates was submitted to the GenBank with accession number as mentioned in Table 1. Using the 16S rRNA, a phylogenetic tree of the three identified microorganisms is depicted in Fig. 1.
Finalization of the microorganisms for the study Various bacterial species take part in the early stages of biofilm formation. Three species of bacteria that are chiefly responsible for the biofilm formation were isolated. To scrutinize the complete range of organisms that are responsible in the early biofilm formation leading to dental plaque, the other likely organisms were procured. Therefore, the Microbial Type Culture Collection (MTCC) cultures were included which were acquired from the Institute of Microbial Technology (IMTECH), Chandigarh, India. The MTCC cultures comprised of 5 microorganisms, of which all were bacteria except Candida albicans (4748) which was a

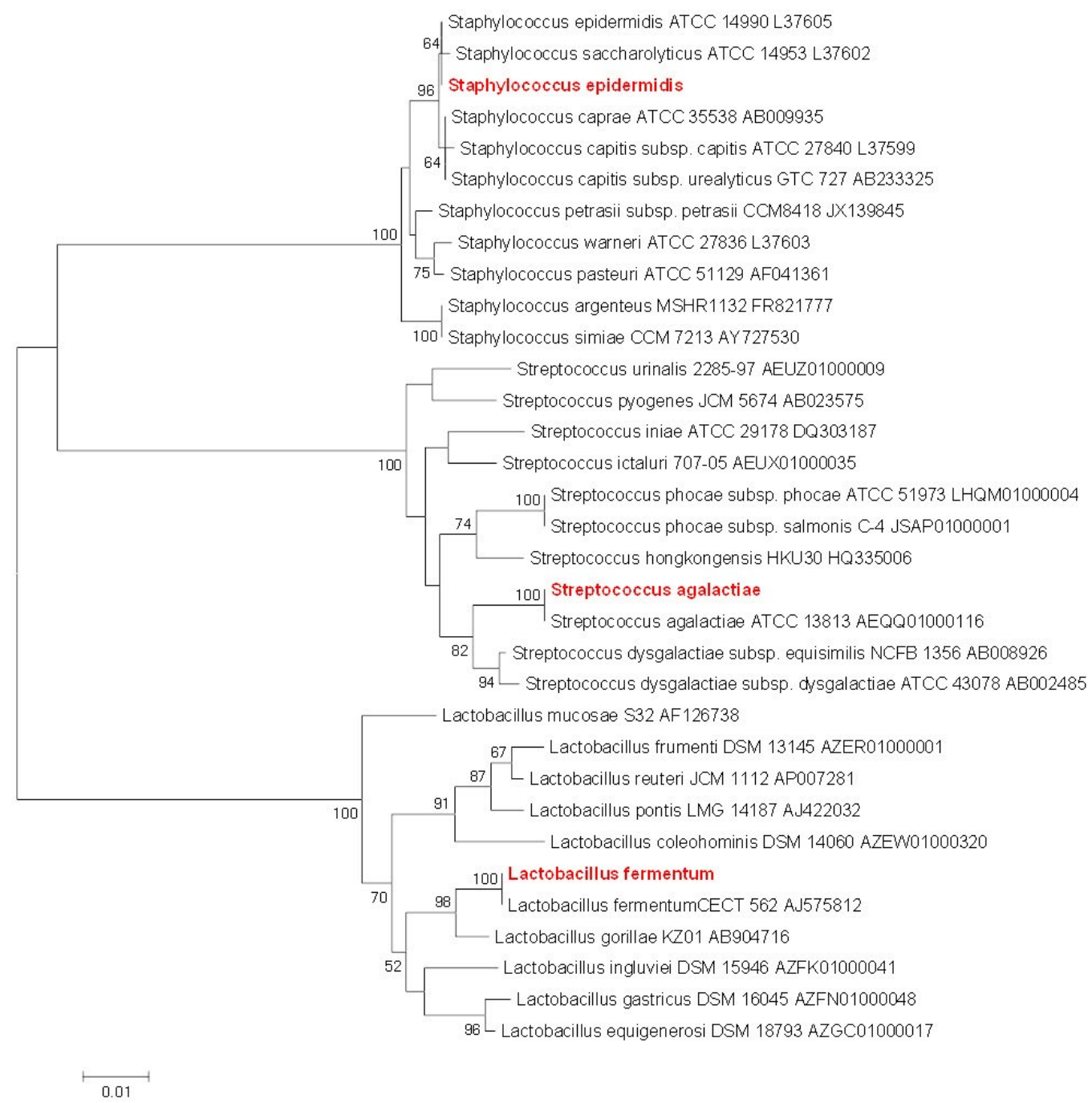

Fig. 1. Phylogenetic tree of the three identified microorganisms (Names are highlited in red). 
fungus. Accordingly, a total of 8 organisms denoted as 'test organisms' were finalized for the study (Table 1).All cultures were cultivated in the various culture media as recommended by IMTECH. Streptococcus mutans (890), Streptococcus oralis (2696), Lactobacillus acidophilus (10307), Lactobacillus rhamnosus (1408), and Candida albicans (4748) were recovered in Brain Heart Infusion Medium, Trypticase Soy Broth, de Man, Rogosa and Sharpe Medium and Yeast Extract Peptone Dextrose respectively. All cultures were held in reserve on their particular solid media.

\section{Development of mouthwash formulation}

Lemongrass essential oil (LGEO) is insoluble in water. By definition, mouthwash must be a hydroalcoholic solution. Thus, direct formulation of mouthwash is not possible and hence, lemongrass must be solubilized by various co-solvents and surfactants to make the mouthwash formulation. ${ }^{9}$

The formula used for mouthwash was as follows: Table 2.

For evaluating the stability, the sample was kept for 3 months at room temperature and the concentration of LGEO was monitored along with the following parameters as

1. Physical parameters,

2. Stability studies

Table 2. Composition of mouthwash

\begin{tabular}{lc}
\hline Ingredient & Quantity \\
\hline Lemongrass Oil & $1 \%$ \\
Propylene Glycol & $50 \%$ \\
Saccharine Sodium & $0.15 \%$ \\
Water & QS \\
Green colour & QS \\
\hline
\end{tabular}

3. Antimicrobial activity

4. Biofilm formation inhibition (Anti-biofilm activity)

\section{Antimicrobial Assay}

Antimicrobial activity of undiluted formulated mouthwash against test organisms was established by means of the standard disc diffusion technique as per Clinical and Laboratory Standards Institute (CLSI) guidelines. ${ }^{10}$ Saline suspension of $24 \mathrm{~h}$ old culture of all the 8 test organisms was prepared according to 0.5 McFarland standards. This $750 \mu \mathrm{L}$ of saline suspension was mixed with 20 $\mathrm{mL}$ of sterilized, cooled Mueller-Hinton agar butt and dispensed in a sterile Petri plate. The plates were set aside to solidify at room temperature. Sterile Whatman filter paper discs pre-soaked $(10 \mu \mathrm{L})$ in mouthwash were positioned on agar surface. Chlorhexidine gluconate, a commercially available mouthwash was used as a positive control. For pre-diffusion, plates were refrigerated at $4{ }^{\circ} \mathrm{C}$ for $30 \mathrm{~min}$. Plates were incubated at $37{ }^{\circ} \mathrm{C}$ for $24 \mathrm{~h}$. The diameter of zone of inhibition was determined in millimeter $(\mathrm{mm})$ and noted. The diameter of zone of inhibition was measured with the help of HI MEDIA antibiotic zone measuring scale. All exposures were carried out in triplicates

Table 3. Physical parameters to evaluate the formulated mouthwash

\begin{tabular}{|c|c|c|}
\hline $\begin{array}{l}\text { Physical } \\
\text { parameters }\end{array}$ & $\begin{array}{l}\text { At zero } \\
\text { hours }\end{array}$ & $\begin{array}{l}\text { After three } \\
\text { months }\end{array}$ \\
\hline Colour & Green & Green \\
\hline Odour & Pleasant & Pleasant \\
\hline Taste & Sweet & Sweet \\
\hline Phase & $\begin{array}{l}\text { Homogenous } \\
\text { single phase }\end{array}$ & $\begin{array}{c}\text { Homogenous } \\
\text { single phase }\end{array}$ \\
\hline Transparency & Clear solution & Clear solution \\
\hline
\end{tabular}

Table 4. Absorbance of citral standard at different concentrations

\begin{tabular}{lcccc}
\hline $\begin{array}{l}\text { Concen. } \\
\mu \mathrm{g} / \mathrm{mL}\end{array}$ & Absorbance1 & Absorbance 2 & Absorbance3 & $\begin{array}{c}\text { Mean } \\
\text { Absorbance }\end{array}$ \\
\hline 10 & 0.03 & 0.031 & 0.029 & 0.03 \\
20 & 0.06 & 0.062 & 0.06 & 0.06 \\
30 & 0.117 & 0.115 & 0.118 & 0.117 \\
40 & 0.12 & 0.126 & 0.123 & 0.123 \\
50 & 0.154 & 0.156 & 0.152 & 0.154 \\
60 & 0.221 & 0.223 & 0.22 & 0.221 \\
70 & 0.231 & 0.235 & 0.236 & 0.234
\end{tabular}


and average value was considered for further evaluation.

Determination of growth of biofilm and antibiofilm activity

Assay for biofilm growth and anti-biofilm activity The growth of biofilm was quantitatively determined according to the "Protocols to study the physiology of oral biofilms" by Lemos et al. ${ }^{11}$ The principle of assay is that the biofilm produced by the organism binds to the crystal violet and the bound crystal violet is later eluted The absorbance of eluted crystal violet is proportion to the amount of biofilm. Assay was carried out in 96 well microtiter plates. Saline suspension of $24 \mathrm{~h}$ old culture of all 8 test organisms was prepared; according to $0.5 \mathrm{McF}$ arland standards. Biofilm medium comprising $1 \mathrm{M}$ glucose (source of carbohydrate) was formulated. $20 \mu \mathrm{L}$ of each 0.5 McFarland standard of microbial culture was dispensed into each well with $180 \mu \mathrm{L}$ of biofilm medium. Wells with a $200 \mu \mathrm{L}$ uninoculated biofilm medium served as negative controls while positive control consisted of $20 \mu \mathrm{L}$ of chlorhexidine with $180 \mu \mathrm{L}$ of medium. Each experiment was carried out in triplicate. Plates were sealed with an adhesive microtiter plate sealer and without any agitation incubated for $24 \mathrm{~h}$ at $37^{\circ} \mathrm{C}$. After incubation, the plates were first blotted on a paper towel to remove culture media, and then were carefully immersed in a large dish with deionised water to remove the loosely bound cells and again blotted on a paper towel. This step was repeated twice. $50 \mu \mathrm{L}$ of $0.1 \%$ crystal violet was added to the test wells. Plates were then incubated for $15 \mathrm{~min}$ at room temperature. The washing was repeated and the plates were later air-dried. To elute the crystal violet bound to the biofilm formed in the wells, $200 \mu \mathrm{L}$ of $33 \%$ acetic acid solution was added to all the wells. Plates were again incubated for 10 min at room temperature. Using a multi-channel micropipette, the entire content of each well was transferred in the respective wells in a new blank microtiter plate. The absorbance was measured at $570 \mathrm{~nm}$ using ELISA reader (Thermo Lab systems

Table 5. Monitoring of citral concentration in formulated mouthwash

\begin{tabular}{lccccc}
\hline $\begin{array}{l}\text { Time } \\
\text { (Month) }\end{array}$ & Absorbance 1 & Absorbance 2 & Absorbance 3 & $\begin{array}{c}\text { Mean } \\
\text { Absorbance }\end{array}$ & $\begin{array}{c}\text { Concen. } \\
(\mu \mathrm{g} / \mathrm{mL})\end{array}$ \\
\hline 0 & 0.284 & 0.285 & 0.284 & 0.284 & 82.495 \\
1 & 0.280 & 0.290 & 0.280 & 0.283 & 82.209 \\
2 & 0.283 & 0.284 & 0.282 & 0.283 & 82.114 \\
3 & 0.283 & 0.283 & 0.282 & 0.282 & 82.019 \\
\hline
\end{tabular}

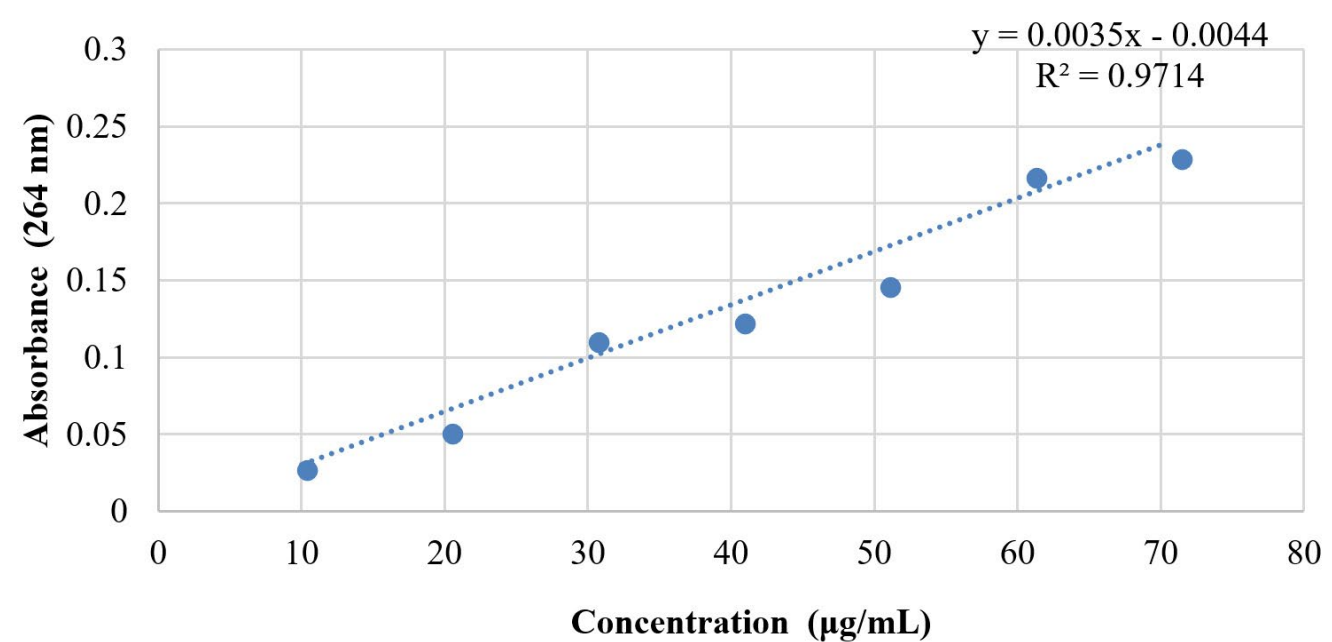

Fig. 2. Standard curve of citral. 
Model No. 352). In anti-biofilm studies, $160 \mu \mathrm{L}$ of medium was subjected to $20 \mu \mathrm{L}$ of culture with $20 \mu \mathrm{L}$ of formulated mouthwash keeping all other steps in the protocol the same. The ability of the mouthwash to inhibit the formation of biofilm was determined as "anti-biofilm activity of mouthwash". Chlorhexidine gluconate was taken as a positive control.

MTT Assay ( 3-(4,5-dimethylthiazole-2-yl)2,5-diphenyltetrazolium bromide cell proliferation assay)

The primary mouse embryonic fibroblast cells NIH 3T3 were procured from NCCS, Pune. Cell lines were preserved in a humidified incubator in a $5 \% \mathrm{CO}_{2}$ atmosphere at $37{ }^{\circ} \mathrm{C}$ in Dulbecco's Modified Eagle's medium (DMEM). 96 well plates seeded with NIH 3T3 cell lines were incubated at $37^{\circ} \mathrm{C}$ in humidified $5 \% \mathrm{CO}_{2}$ atmosphere for $24 \mathrm{~h}$. The cell lines exposure was carried out for cell control, DMSO control, formulated mouthwash

Table 6. Antimicrobial activity of formulated mouthwash

\begin{tabular}{lcc}
\hline Test Organisms & \multicolumn{2}{c}{ Zone of Inhibition (mm) } \\
\cline { 2 - 3 } & Chlorhexidine & $\begin{array}{c}\text { Formulated } \\
\text { Mouthwash }\end{array}$ \\
\hline S.mutans & 30 & 25 \\
S.oralis & 32 & 27 \\
L. acidophilus & 36 & 31 \\
L. rhamnosus & 35 & 22 \\
C. albicans & 34 & 28 \\
S. agalactiae & 30 & 22 \\
S. epidermidis & 29 & 21 \\
L. fermentum & 30 & 23 \\
S. mutans & 30 & 24 \\
\hline
\end{tabular}

and LGEO $1.5 \%$. The exposure was made in triplicate and incubated further for $48 \mathrm{~h}$. Then 10 $\mu \mathrm{l}$ of $5 \mathrm{mg} / \mathrm{ml}$ of MTT dye was added to all the wells and incubated for $4 \mathrm{~h}$ in dark. Formazan crystals were solubilised using $100 \mu \mathrm{l}$ of DMSO and after keeping plates in dark for $15 \mathrm{~min}$, the absorbance was measured at $570 \mathrm{~nm}$. To confirm the results the assays were performed at least twice. The survival of cells was measured as absorbance of the mean of triplicate wells in comparison to that of control.

\section{RESULTS}

Evaluation of physical parameters of mouthwash

The physical parameters of the in-house developed mouthwash kept at room temperature in the plastic container were evaluated for 3 months and are as shown in Table 3.

\section{Stability studies}

The stability of formulated mouthwash was evaluated by monitoring the stability of the principal/major component of LGEO that is citral. Thus for evaluating the stability of formulated mouthwash, the mouthwash sample was kept at room temperature in the plastic container for 3 months and the concentration of citral was monitored at monthly intervals.

For the stability testing, citral stock standard was made in DMSO from which working citral standards in the range $10 \mu \mathrm{g} / \mathrm{mL}$ to $70 \mu \mathrm{g} /$ $\mathrm{mL}$ were prepared so that the absorbance of the standards comes within the sensitive measurable scale of the spectrophotometer. The absorbance of citral measured at $264 \mathrm{~nm}$ at the different concentrations is as per Table 4.

Table 7. Biofilm formation inhibition activity of formulated mouthwash

\begin{tabular}{lcc}
\hline $\begin{array}{l}\text { Test } \\
\text { Organisms }\end{array}$ & $\begin{array}{c}\text { Mean Absorbance at } 570 \mathrm{~nm} \text { as index } \\
\text { of biofilm formation }\end{array}$ \\
\cline { 2 - 3 } & $\begin{array}{c}\text { in absence of any known } \\
\text { inhibitory agent }\end{array}$ & $\begin{array}{c}\text { in presence of formulated } \\
\text { mouthwash }\end{array}$ \\
\hline S. mutans & 0.303 & 0.145 \\
S. oralis & 0.256 & 0.146 \\
L. acidophilus & 0.292 & 0.116 \\
L. rhamnosus & 0.413 & 0.137 \\
C. albicans & 0.342 & 0.179 \\
S. agalactiae & 0.259 & 0.159 \\
S. epidermidis & 0.233 & 0.135 \\
L. fermentum & 0.307 & 0.134 \\
\hline Journal of Pure and Applied Microbiology & 179
\end{tabular}


The mouthwash was diluted 10 times and absorbance at $264 \mathrm{~nm}$ was recorded. The concentration of citral in the mouthwash was then determined from the standard curve equation and was found to be $82.5 \mu \mathrm{g} / \mathrm{mL}$. This was monitored at a monthly interval for three months. The absorbance and the concentration determined by calculation were found to be almost the same for three months as shown in Table 5.

This experiment demonstrated that there is no change in the citral concentration thereby reflecting the stability of citral which is the principal/major component of LGEO and thus indicated the stability of LGEO in the formulated mouthwash.

Antimicrobial activity of LGEO based mouthwash

The undiluted formulated mouthwash was exposed to a set of 8 test organisms to determine its antimicrobial activity. The mean zone of inhibition for the different test organisms and its comparison with chlorhexidine is as per Table 6.

This experiment clearly demonstrated that formulated mouthwash has the desirable and expected antimicrobial activity and there appears to be no loss in the antimicrobial activity of LGEO on formulation of mouthwash.

\section{Anti-biofilm activity of LGEO based mouthwash}

The formulated mouthwash was also subjected to the same set of experiments against the 8-test organism to determine its anti-biofilm activity. The results of biofilm formation inhibition using undiluted formulated mouthwash are as per Table 7.

\section{Cytotoxicity test}

Cytotoxicity testing was carried out by MTT assay. The MTT assay was carried out for cell control, DMSO control, formulated mouthwash and LGEO $1.5 \%$. The cell control contained the viable cell lines in an appropriate buffer; DMSO was a solvent control to rule out any cytotoxicity in DMSO itself; while formulated mouthwash and LGEO (1.5\%) are those whose cytotoxicity was evaluated. The results of MTT assay are as shown in Fig. 3.

\section{DISCUSSION}

The results clearly indicated that neither LGEO nor the formulated mouthwash has lowered the formazan formation (absorbance) in MTT assay. This finally established that the formulated mouthwash and LGEO has no cytotoxic activity. Our result regarding the LGEO as non-cytotoxic is in agreement with that of the recently reported study of Madeira et al., ${ }^{12}$ who demonstrated that LGEO provided a cellular viability similar to the phosphate buffer saline group taken as the control group and also reported that LGEO is well-known to be non-toxic to human cells.

There are studies on the lemongrass oil mouthwash by Satthanakul et al., ${ }^{13}$ in which the antimicrobial activity of lemongrass oil mouthrinse was examined using broth microdilution assay and the disc diffusion method where it was

\section{MTT Assay}

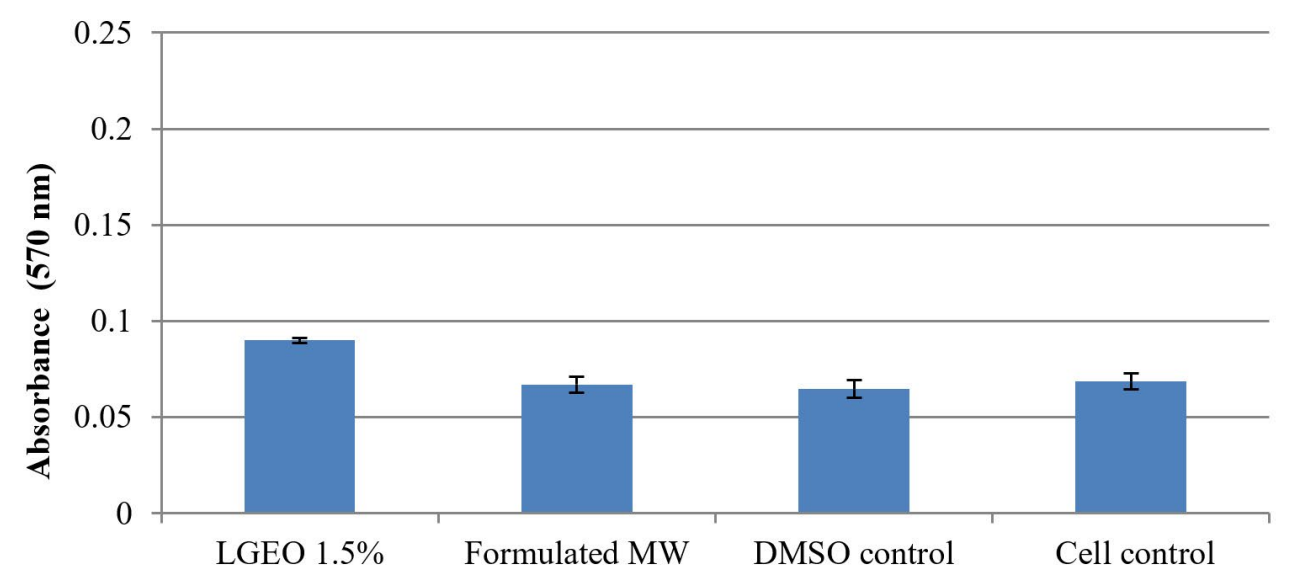

Fig. 3. Absorbance of formazan as an indicator of cells viability. 
found to be effective against Aggregatibacter actinomycetemcomitans and Porphyromonas gingivalis but less effective against Streptococcus mutans. Our result showed that the formulated lemongrass mouthwash was effective against the test organisms S.mutans, S. oralis, L. acidophilus, L. rhamnosus, C. albicans, S. agalactiae, S. epidermidis and $L$. fermentum.

Moreover, the LGEO is widely used by international brands like Nivea in their daily routine beauty products like soaps, shampoos, deodorants/Roll-Ons etc. LGEO is also commercially available internationally on amazon (www. amazon.com) as a perfect ingredient for flavoring candy or chocolate and also for aromatherapy and crafting.

\section{CONCLUSION}

The prepared mouth wash was found to have required stability in terms of physical and chemical parameters and has no cytotoxic activity. The study clearly demonstrated that the LGEO based mouthwash has considerable antimicrobial and anti-biofilm activity against the organisms responsible for dental plaque.

\section{ACKNOWLEDGMENTS}

The authors would like to thank Dr. M.R. Bhalekar for support in formulation of mouthwash. The authors are also grateful to Dr. A.S. Moghe for providing all necessary facilities to conduct MTT Assay.

\section{CONFLICT OF INTEREST}

The authors declare that there is no conflict of interest.

\section{AUTHORS' CONTRIBUTION}

All the authors have made a substantial, direct and intellectual contribution to the work, and approved it for publication.

\section{FUNDING}

None.

13. Satthanakul $P$, Taweechaisupapong $S$, Paphangkorakit J, Pesee M, Timabut P, Khunkitti W. Antimicrobial Effect of Lemongrass Oil against Oral Malodor Microorganisms and the Pilot Study of Safety and Efficacy of Lemongrass Mouthrinse on Oral Malodor. J Appl Microbiol. 2014;118(1):11-17. doi: 10.1111/ jam.12667

\section{AVAILABILITY OF DATA}

All datasets generated during this study are included in the manuscript.

\section{REFERENCES}

1. Kukkamalla MA, Bhat GS, Pentapati KC, Goyal R. Antiplaque Efficacy of Lemongrass Oil Mouthwash An invitro Study. Global Journal of Medical Research. 2012;12(7):18-23.

2. Steinberg D, Weiss El ,Feldman M, Ofek I. Effect of a high-molecular-weight component of cranberry on constituents of dental biofilm. J Antimicrob Chemother. 2004;54(1):86-89. doi: 10.1093/jac/dkh254

3. Balunas MJ, Kinghorn AD. Drug discovery from medicinal plants. Life Sci. 2005;78(5):431-441. doi: 10.1016/j.Ifs.2005.09.012

4. Ambade SV, Nagarkar SS, Deshpande NM. Evaluation of Lemon Grass Essential Oil as anAntimicrobial Agent Against clinical isolates ofMRSA, VRSA and VRE. International Journal of Biotechnology and Biochemistry. 2017;13(4): 377-390

5. Salam R, Sarker BK, Haq MR, Khokon JU. Antimicrobial activity of medicinal plant for oral health and hygiene. Int J Nat Soc Sci. 2015;2(1):1-12.

6. Ambade SV, Deshpande NM.Antimicrobial and Antibiofilm Activity of Essential Oil of Cymbopogon citratus against oral micro flora associated with dental plaque. European J Med Plants. 2019;28(4):1-11. doi: 10.9734/ ejmp/2019/v28i430143

7. Pidiyar VJ, Jangid K, Patole MS, Shouche YS. Studies on cultured and uncultured microbiota of wild culex quinquefasciatus mosquito midgut based on $16 \mathrm{~s}$ ribosomal RNA gene analysis. Am J Trop Med Hyg. 2004;70(6):597-603. doi: 10.4269/ajtmh.2004.70.597

8. Janda JM, Abbott SL. 16S rRNA genesequencing for bacterial identification in the diagnostic laboratory: Pluses, perils, and pitfalls. J Clin Microbiol. 2007;45(9):2761-2764.doi: 10.1128/JCM.01228-07

9. Vranic E, Lacevic A, Mehmedagic A, Uzunovic A. Formulation ingredients for toothpastes and mouthwashes. Bosn J Basic Med Sci. 2004;4(4):51-58. doi: 10.17305/bjbms.2004.3362

10. Clinical and Laboratory Standards Institute, TwentySecond Informational Supplement. 2012;32:M100.

11. Lemos JA, Abranches J, Koo H, Marquis RE, Burne RA. Protocols to study the physiology of oral biofilms. Methods Mol Biol.2010;666:87-102. doi: 10.1007/9781-60761-820-1_7

12. Madeira $\mathrm{PL}$, Carvalho $\mathrm{LT}$, Paschoal $\mathrm{MA}$, et al. In vitro Effects of Lemongrass Extract on Candida albicans Biofilms, Human Cells Viability, and Denture Surface. Front Cell Infect Microbiol. 2016;6:71. doi: 10.3389/ Front Cell Infect $M$

\section{ETHICS STATEMENT}

Not applicable. 